\title{
EDUTAINMENT IN THE ARMED FORCES OF THE REPUBLIC OF POLAND
}

\author{
Agnieszka SZCZYGIELSKA \\ Faculty of Command Management, War Studies University, Warsaw, Poland; a.szczygielska@akademia.mil.pl, \\ ORCID: 0000-0002-8753-9484
}

Purpose: The aim of the study is to show that war games and simulations used in the Armed Forces to improve military personnel bear the hallmarks of edutainment.

Design/methodology/approach: The study is of a theoretical and empirical nature. The theoretical methods used, such as: analysis, synthesis, inference, analogy and abstraction based on literature and other available media specialist sources on the discussed topic. The use of empirical methods was in the form of observations and methods of collecting judgments and opinions with the informal interview technique with representatives from the Centre for Simulation and Computer War Games (CSiKGW).

Findings: This researches were aimed at explaining the essence of the concept of edutainment, the concepts related to it, explanation of determinants determining the development of new forms of improvement off human resources in organisations and in the Armed Forces of the Republic of Poland. It was shown that edutainment is new, interesting form of educatin in so specific hierarchical organisations, such as Armed Forces.

Originality/value: Author has obtained expert's opinions on the perception of war games and simulations as an effective form of improvement combining learning with elements of entertainment, i.e. as edutainment. Additional, in the theoretical research showed that edutainment is a successful form of learning and creating knowledge in innovative way.

Keywords: Armed Forces, edutainment, improvement, war games, simulations.

Category of the paper: Literature review; Research paper.

\section{Introduction}

When improving staff, developing knowledge and disseminating it in an organisation, it is necessary to use various forms of employee training, as well as development, shaping and conversion of knowledge. Training methods can be divided into three basic groups: 
- information and demonstration methods (enrich knowledge),

- simulation methods (enrich knowledge, skills and attitudes),

- improvement methods in action (enrich knowledge, skills and attitudes).

In order to maximally increase the efficiency of work, the fullest absorption of knowledge resources, shaping more and more valuable competences, forms of education and improvement, should be applied in such a way that the participants engage the most actively. In this form, it is important to analyse case studies, solve problem situations that could potentially occur, create scenarios of events and reactions in the event of their implementation, as well as exercise the exchange of roles and positions. The development of staff conducted in such a way changes and enriches its level of knowledge, and additionally improves the behaviour, attitudes and reactions in specific situations that may possibly occur in reality. The methods of activating participants have the greatest absorption of knowledge, because information is absorbed not only through listening, but also through real activities and cooperation with other people.

Nowadays, in the face of faster technological development and the use of innovative techniques and tele-IT tools, new methods of intellectual stimulation are constantly being modified and developed. The methods of educating staff at the same time verify the numerous predispositions and competences of those trained, and the shaped capital of knowledge is one of the most valuable resources of each organisation.

Not all methods serving these purposes are in the form of serious lectures or classes nor based on listening to experts or passively analysing specialised materials. Often they are combined with activating elements, where the staff must perform certain tasks independently, sometimes outside the workplace, in a different team, assuming different operating conditions, a different role, etc. Such exercises are a springboard and a change from everyday life. They are a different form of learning than traditional methods, and therefore they constitute a certain dose of attractive entertainment. They strengthen the will, as they are something new, interesting and less burdensome. However, this does not mean that knowledge is not transferred at the moment. On the contrary. In such a situation and with the attitude mentioned above, the mind is more receptive, open, ready for active and more engaged work, because it does not read such a form of training as difficult, hard science, but as a slightly educational entertainment formula. Such a formula, where learning and entertainment are combined, is referred to as edutainment.

The aim of the study is to show that war games and simulations used in the Armed Forces to improve military personnel, bear the hallmarks of the mentioned form of training, i.e. edutainment. The study is of a theoretical and empirical nature. The theoretical methods used, such as: analysis, synthesis, inference, analogy and abstraction based on literature and other available media specialist sources on the discussed topic, were aimed at explaining the essence of the concept of edutainment, the concepts related to it, explanation of determinants determining the development of new forms of improvement off human resources in organisations and in the Armed Forces of the Republic of Poland. The use of empirical methods 
in the form of observations and methods of collecting judgments and opinions with the informal interview technique with representatives from the Centre for Simulation and Computer War Games (CSiKGW) was conditioned by the specificity of the issue under consideration and aimed at obtaining expert opinions on the perception of war games and simulations as an effective form of improvement combining learning with elements of entertainment, i.e. as edutainment. The Centre is the only unit in the Armed Forces that implements programmes and projects including complex games and simulations for the Polish Army. The Centre is the most competent unit that can speak on the subject of simulation and computer war games from the point of view of improving staff performance, as well as related issues and complementary matter considered solely as edutainment. Therefore, it seems reasonable to accept the information obtained from the representatives of this unit as the opinions of specialists of the Armed Forces in the discussed topic.

The study also has the character of subjective deliberations and the presentation of opinions also arising from the observation of the military environment, the activities carried out in the ministry and other informal conversations, while maintaining the anonymity of the interlocutors. A synthetic, thematic summary of conclusions and thoughts on the subject of edutainment and its role in the military has been addressed in the form of this study.

\section{Edutainment as an effective way of teaching}

At a time when information and knowledge have become the key resources in an organisation conditioning the achievement of success and market advantage, interest in shaping intellectual resources and expanding employee knowledge is becoming more and more important. Recently, in the circles of new methods of improvement using everyday solutions, we hear more and more about the phenomenon of edutainment. The name "edutainment" comes from English and is a combination of two words, i.e. education and entertainment, and its meaning expresses a combination of science and entertainment elements. Less often, one can come into contact with the Polish name - edurozrywka. Edutainment refers to recreational learning and knowledge transfer in non-traditional informal conditions, including: at home, museums, information centres and observation platforms. Edutainment supports 'lifelong learning', which focuses on the assumption that learning should not be limited to school-age people (Moss, 2009, p. 248; see also: Tummons, Ingleby, 2014, p. 45). It has been assumed that entertainment, emotions and feelings are the opposite of, thinking, reason and science. Practice shows, however, that emotions and reason can be combined in a balanced proportion. In a synergistic combination, they result in valuable effects for human development. That, what affects in a person emotions makes him to act. Whether they are positive emotions 
or negative, they activate the individual. Many forms of learning evoke emotion from nervousness, anger and fear, ending with pleasure, joy, passion and excitement.

Many television programmes, films, Internet broadcasts, computer games, trainings and exercises in an organisation with elements of play bring about different emotions in the participants or recipients. This is intentional, because feeling them with even greater involvement helps one absorb the content and increases the expectation for more. The ultimate goal is to broaden knowledge, develop abilities and skills, extend competence or verify this, change one's attitudes towards value systems and principles and to increase awareness on various topics.

The beginning of the phenomenon of edutainment is perceived to have begun in the 1950s. At that time, various awareness programmes were broadcast, while in the 1970s, Miguel Sabido (perceived as the best-known practitioner and theoretician of edutainment) began broadcasting a TV series of short stories in Latin America that contained numerous educational content regarding pro-health education, as well as topics related to family life, emphasising the role of education, etc. Currently, you can see more and more programmes (e.g. Discovery Chanel, Animal Planet, History, BBC Earth), movies (historical, about life on other planets, about cyberspace, etc.), tournaments (e.g. 1 out of 10, Millionaire, I Love You Polish) and broadcasts with highly educational values for both children and adults (regarding cooking, exercise, health and various diseases, etc.). In the field of media, this also applies to radio, newspapers, magazines and the Internet. Very popular are various types of health blogs, such as those relating to travel and presenting the curiosities of other cultures and nations ${ }^{1}$. On YouTube, a large number of people (so-called youtubers) periodically mix short educational videos for their fans about the teaching content. For recipients, this is beyond learning some kind of entertainment - when they watch another few minutes of advice, reports and shows. At the same time, however, in a pleasant way, they absorb knowledge, e.g. about the culture of another country, proper exercise or healthy cooking.

It is also worth mentioning the large number of computer games appearing on the market at a very fast pace which deal with educational issues, including: health topics (e.g. simulations of operations, saving the health and life of virtual characters), architecture topics (e.g. building design, building, renovation, reconstruction), farm management (where you should take care of crops, pets), as well as creating and managing a sports team. They help to teach a given problem, to experience in the virtual world the important consequences of their decisions and to strengthen the sense of duty, responsibility and to shape situational awareness - here without the risk of real negative consequences in the case of mistakes made.

\footnotetext{
${ }^{1}$ An interesting educational project to talk about was the movie "The Yellow Card", broadcast in Zimbabwe and addressed to people for the purpose of education on the topic of AIDS and for those who are underage in pregnancy. It made people aware and increased the awareness of the sphere of health and unplanned pregnancy.
} 
In one of the schools in Poland, research was conducted in the field of education through games, on the basis of which a short report on the use of computer games in school didactics was created (Read more about this topic at http://bajkiozobotow.pl/wp-content/uploads/ 2016/11/grydaktyka-opracowanie.pdf).

It should be emphasised that many modern games are more than just pure fun. Many of them provide the opportunity to personalise the game, which means that players spend more money on them more willingly. Research shows that 2017 was the most profitable year for digital games and interactive media. A new look at digital games, the continuous development of new segments, such as e-sport, video content for games and virtual reality, led to the creation of a dynamic market that does not show any sign of slowing down. It turns out that one in three people in the world ( 2.5 billion) play free games on computers and mobile platforms, and almost half of all players are women. Consumers in 2017 spent USD 14 billion more on mobile games than in 2016. It is forecasted that global interactive games and the media market will increase revenues by $80 \%$ by 2020 . So-called "gaming" has become a basic tool in virtual reality, whereby experience and solutions based on geolocation are gaining momentum. It is expected that by 2020, video content will rank second-best in the software segment, reaching 3.3 billion USD. (SuperData, 2018, Trends and Insights on Games and Interactive Media, 2017). Players will spend over USD 4.5 billion on virtual games by 2020, which more than 30 times today.

Edutainment includes movies, television programmes, radio, Internet relations, blogs, various games (from board games to field games to computer games), theatre performances, special meetings from social networks in interest groups, events organised by organisations for employees (Szaban, 2011, p. 328) or out-of-town workshops, provided that they are designed and directed to achieve educational goals and increase the awareness of recipients on various topics, broaden knowledge, improve skills and abilities, strengthen intra- and interpersonal traits and shape attitudes, value systems and social norms.

A large percentage of games that are popular and breaking popularity records relate to wars, armed conflicts or battles. Fascination with the subject of army, weapons, fighting, martial arts, psychological techniques used in certain units and survival in difficult conditions is clearly noticed, and not only among young people. Many adults are also fascinated with weapons, wear outfits stylised after field uniforms or buy original military equipment during special sales or learn military techniques and shoot or participate in courses organised by special services (in Poland, for example: Grom). Such interest in the subject of the army is referred to as Militainment (the name was created from the combination of two English words, i.e. Military and Entertainment, understood as "Military Entertainment"). The first time this word appeared was in an article by James Poniewozik published by Time magazine in 2002, where the author described the developing phenomenon (Poniewozik, 2002).

"War is a very attractive topic for the media, because it meets the essential criteria 'focus' on issues undertaken" (Wrzosek, 2018, p. 216). Interest in the subject of war sometimes takes on perverse forms and goes in an ethically undesirable direction. Fighting, violence, weapons 
and waging war are seen in games and media as normal and natural. Some, however, want something more, namely something that is available to a small group of recipients and which shows in a more emphatic and literal way the face of war. Common are several videos showing an execution or a murder in detail or videos and photos containing real crime scenes and details of the people killed. Pictures and films filled with situations which, due to respect for the victims, should remain hidden from the public cause great excitement among a certain group of recipients. Photos of maimed, mutilated, torn, burnt human remains or movies with the shooting, undercutting throats, cutting heads, brutal rapes they generate more and more curiosity, fascination and sometimes become even an object of fetishization. This phenomenon, in a generalised form, is referred to as War Pornography ${ }^{2}$.

The phenomenon described in its drastic form is a wrong direction of society development, it is even perversion and extremes. In many societies, unfortunately, this is happening and it is a phenomenon that naturally accompanies every progress, because every progress causes a solstice and some border is broken. It is already known, for example, that addiction to the Internet and games causes alienation and sometimes leads to the death of the so-called hikikomori. We can mention here about workaholism leading to self-destruction and death called karoshi, additionally e.g about dependence on fast food and desire to become the heaviest, fattest people in the world (phenomenon mainly in the USA) or about dependence on fast sex and adrenaline (casual sex with people infected with HIV, where the risk of infection is big, creates additional excitement). One should be aware of the existence of this type of phenomena, but also remember that the progress of technology determines the development of societies and the economy, and with every change, there are always some of adverse consequences. There is very limited specific and extensive research in the field of edutainment, as there are rather studies commissioned by selected companies or schools or observations of the effects of a given educational and entertainment activity. The research is conducted mainly in the form of subjective observations of trainers and people teaching, as well as people implementing educational projects; and among satisfied people who have completed this form of education with elements of entertainment. The positive effects of these undertakings are widely noticeable, and thus their implementation is more and more often taken up in a variety of formulas, which is underlined in this study.

\footnotetext{
${ }^{2}$ It is worth reading the information on the NowThatsFuckedUp.com website, founded and administered by Chris Wilson and addressed to American soldiers stationed in Iraq and Afghanistan. Its only purpose was to exchange pictures of victims of wars, which soldiers could use on the site as money giving them free access to pornographic images. In 2006, however, the site was ordered to close, and its owner was banned from running such activities until 2011. More information on the website: https://www.documentingreality.com/forum/view.php?pg=ntfu.
} 
The research of the coaching company in the topic presented in the study shows that edutainment as a key coaching tool is needed and effective when: (Gammadiscover)

- experienced employees are bored with traditional types of training, but there is a need to further improve them,

- it is necessary to change attitudes, behaviour and motivation when the employees have the potential and experience, but do not use it in practice,

- at the moment when the organisation of an integration meeting is planned, where, apart from integration, there are plans to organize games that inspire and develop the intellect of the staff,

- there is a need to create a better image of the organisation,

- there is a need to prevent organisational disorder and stimulate more creative work and enrich the daily work system.

The study emphasises the role of events and projects in the field of edutainment, which are implemented with awareness of socially correct education, learning through entertainment elements, where the absorption of knowledge occurs in a state of greater relaxation than every day, while doing standard task and duties. In many social and professional groups, education becomes an integral part of leisure, and the demand for entertainment education is becoming more and more interesting (Reinhardt, 2007, p.163). In the Armed Forces, the phenomenon of edutainment is also noticeable.

Within the army, elements of games, simulations and ICT solutions have been used for a long time, bearing the hallmarks of entertainment for training and improving staff, which leads to the acquisition of appropriate competences (Majewski, 2013, p. 50).

\section{The edutainment phenomenon in the army}

In the period of striving to transform into a Army of the Future, fully network-centric and capable of fighting in cyberspace, it is increasingly required to consciously manage knowledge in the Armed Forces. With time, more and more emphasis will be placed on comprehensive and diverse forms of education, improvement and staff development.

In the Armed Forces, edutainment is a little-known theoretical concept, but in practice, the methods corresponding to this phenomenon are used in an intuitive way. However, research in this area is not popular, but only represents a fraction of the analysis of education and training. Activities that have a character of science combined with elements of entertainment are treated in the army as an additional and supportive tool for improving staff performance, which brings interesting results, because it is a new form, distracting us from everyday life. It is far from traditional training formulas, which are not always well-suited to the topic. 
The role of war games and simulations in improving military personnel and educating outstanding specialists of the Armed Forces of the Republic of Poland is very often emphasised. It has become a natural and necessary consequence of progress in the present times of computerisation and functioning in cyberspace. War games and simulations are a serious, complex and highly substantive type of training of soldiers. It is worth recalling the forms of exercises that stand out in the Polish Armed Forces, i.e.:

1. war game (strategic, operational),

2. command-staff exercise (skeletal, computer assisted, on maps),

3. staff training.

Another forms of tactical exercises for example: tactical-special exercises; preparatory exercises and historical-geographic travels, various workshops, conferences, seminars and lectures reflect much less than the above-mentioned conditions of the actual battlefield. However, each form of exercise develops and improves specific operational skills.

As part of the simulation, in turn, one should indicate three of its key types, i.e.:

1. constructive - a computer plays the main role, serving the staff;

2. virtual - there is here: virtual equipment, a man and, a properly created environment, e.g. training simulator.

3. real - in the so-called real environment, e.g. a training ground and, of course, people.

The aforementioned types of exercises and simulations are not typical forms of training and staff improvement. This is why it is necessary to recall the phenomenon of edutainment here. This form of improvement is also extremely effective in the army, and it is in these types of exercises and simulations that one can see its distinct characteristics. Despite the fact that these are advanced exercises requiring specialist knowledge, high mental effort, a high level of engagement and often increasing levels of stress, they also have an extent of entertainment and provide a sense of pleasurable detachment from traditional forms of learning. They are a diversification of reality and an attraction during the entire learning process. This combination of science and a useful type of entertainment is a phenomenon increasingly popular in modern edutainment training circles. In the situation of conducting war games, mixed task teams are often created, i.e. the officers/practitioners actually come from different cells, with a variety of specialties and roles. Often during the exercises, the functionaries assume a different role than before and perform other functions than those on a daily basis, which allows one to verify the flexibility of one's competence, system thinking ability, knowledge of other units, ability to adapt to changing conditions and situations, and it shapes the operative-tactical imagination. From the point of view of human resources management, this is an outstanding example of enriching work and knowledge, as well as expanding competences. Performing successive team activities allows for spontaneous learning about each other, while also discovering gaps in the knowledge of others, but also of ourselves. When making decisions, it becomes necessary to exchange information and share knowledge within working teams (staff functional cells) and task groups. It develops and improves qualifications in this field, as well as communication 
skills and typical interpersonal skills. The sharing of knowledge, therefore, affects learning. Often, in the course of an exercise, to resolve a given tactical or operational problem the knowledge, which is possessed is sometimes not enough, so it necessary to acquire new one knowledge. To get the information you need, you can draw from external sources (the environment of the combat system) and internal sources (exercising elements). Therefore, the ability to acquire knowledge and the ability to locate it is verified here. All this affects intellectual arousal, as it works best when the trainee (trained) takes an active part in something and does not only use pure theory or conduct an observation of the phenomenon. Through the different behaviours of participants at different moments of the game, you get to know your fellow players from different sides and so does the analytical team that assesses players (e.g. team analysis and evaluation exercises). In the course of the exercise, you can also verify views, ideas, speed and brightness in associating, combining facts and the effectiveness of persuading others to your own reasons, thereby getting to know the opinions and beliefs, values, principles and personal and professional priorities of other participants in the learning process. In games and simulations, the consequences of all decisions, ranging from the everyday ones, which often under stress can be unconsciously omitted as too obvious and in fact determine the success of the mission (e.g. planning rest, soldiers, meal breaks, delivering fuel to vehicles or providing enough ammunition for a specific action), ending with the most serious and complex decisions involving when, where and in what number and type of troops to make the attack and on what objects of the opponent and in what arrangement.

In the event that other teams take part in the game, there is a natural mobilisation, greater effort and commitment forced by competitiveness and the will to succeed. None of the troops wants to be in a losing position, with more mistakes, so they try even harder. Such competition is undoubtedly a kind of entertainment, where softened are the nuisance of the didactic dimension of these exercises and simulations. As a result of the competition, the weaker team can learn from a stronger (better) one, get to know the decision-making process, as well as take into account variables, indicators and subsequent actions. Such learning from the best can be used further, for example in the form of introducing own developed methods of action into the knowledge base (for example in SWD). This will be part of the best practice, and when others benefit and successfully verify these recommendations, lessons learned will be created in practice. These could be small but significant elements to the future knowledge management system in the Polish Armed Forces.

For the purpose of obtaining additional and supplementary information regarding the issue of edutainment, an informal interview was conducted with a representative of the Centre for Simulation and Computer War Games (CSiKGW) at the Academy of War Art. This conversation additionally highlighted some aspects of the discussed forms of science as a sophisticated and highly substantive form of edutainment. 
It should be emphasised that in the Simulation Centre, far-reaching cooperation with various units and organisations in the exchange of experience, mutual support, as well as exchange of knowledge, is declared. There is active participation in numerous conferences and symposia, as well as presentations of simulation systems in the scope of what, when and how they can be modernised and used. In the situation when the necessity for corrections, changes or modernisation are noticed, then a group request is made to the superiors in this respect. In addition, if the subject matter of the proposal falls within the priorities, it is implemented and financed by NATO. Efforts are also being made to ensure that the new solutions fully meet the expectations of the current soldiers and corresponded to the conditions they would face in reality. A novelty in the Centre is, for example, the application of the JTS (Joint Targeting System), which is useful in, for example in crisis management during planning and conducting joint operations. the reign and conducting operations of combined forces. It was clearly emphasised that JTLS (Joint Theatre Level Simulation) is a very valuable solution, used not only in the educational process of officers. It is an interactive real-time simulation system modelling the activities of the army, police, municipal guards, border guards, fire brigades and ambulance services, as well as reflecting the conditions of the area of operations and crisis events. The JTLS system illustrates the most important aspects of war and takes into account non-military cells that are extremely important in emergency situations. It is used to conduct computer-assisted exercises, i.e. CAX (Computer Assisted Exercises). In a computer environment, similar conditions are created to make decisions that soldiers would face in a military operation. It is important that the system works with the so-called JCATS (Joint Conflict and Tactical Simulation), which is a system of connected servers, terminals, software and a database in which simulated scenarios are collected. It is commonly said that JCATS does not check the combat preparation of soldiers, but the ability to plan military operations by commanders. Thanks to this, it is verified whether orders issued by commanders can be carried out in given conditions (Polska Zbrojna, 2012).

The words of former NATO commander in Europe, General Philip Breedlove, are remarkable: "War games are not played to win, but to learn." For this reason, the opinion of an expert from the Centre on the characteristics and competences that develop, shape and verify soldiers as a result of participation in computer games and simulations seemed to be interesting. It should be remembered, that the simulations makes the environment and equipment more real. In the case of exercises in battle field, there could be various restrictions e.g. noise standards, biology, environmental protection, rules of coexistence in society, care for animals, etc. that must be respected, therefore important is the fact, that these previously mentioned restrictions during the simulations don't exist. Thus, it is possible to accept conditions such as those at the moment of threat to the security of the State so that a whole range of decisions and the dynamics of operations can be freely examined. 
Elements that are relevant and subject to verification are mainly:

- time-taking subsequent actions, the quality and speed of decisions (on the map, they remain without any noticeable consequences, and in the simulation, all consequences are visible),

- adopted solution - one can see in the action scenario what the other party has pointed out, what was important to them, compare the priorities, accepted assumptions and rules of the opposite side,

- the personality of the exercisers - it is checked what values a person confesses on a specific command or managerial position, and what is crucial in fighting which is crucial in conducting a battle,

- knowledge - the resources of operational knowledge are verified,

- the staff's experience in operating in given conditions,

- observance of the rules of armed conflicts - the knowledge of law, regulations and internal arrangements is controlled,

- organisational skills - the following are checked: dutifulness, responsibility, self-control and ability to organize (e.g. whether the persons responsible for logistics/technical protection, materials, inventory, etc. have carried out their tasks properly, also by designing and anticipating further actions. In this way they will give the opportunity to take further actions).

The analysis team at CSiKGW assesses in this situation the work of both staff and individuals. In the case of additional simulations, you can also assess the mental and physical predispositions of the exercisers. For example, using virtual simulation in the form of a load capsule, you can verify physical and psychotronic predispositions, as well as the response rate to external stimuli. By the way, at all times during the exercises, soldiers are perfecting English, specialised vocabulary as well as commands and names used throughout the world in the field of the army and beyond.

In the discussed simulations, it is very difficult to model and set parameters for these simulations, because you need to have vast knowledge and experience from operational reality, which means that you should determine what consequences in the simulation will cause a given grenade to drop into a group of 10 soldiers or where paratroopers will land in a given situation and in a given weather and what external conditions of the operational and tactical situation are conducive to such activities. Parameterisation is a very difficult and demanding task, which largely determines the subsequent assessment and verification of the effects of the actions and decisions that are maximally close to the real ones. This is also associated with high efficiency of training of the armed forces using computer simulations and games. Equipment and software from PIT-RADWAR (PIT-RADWAR n.d.), mainly in the field of automated command systems, are also important and valued. Practitioners work on command systems in conditions of real staff work and use IT tools in their everyday operations. During the exercises, 
they learn additional functional elements and acquire technical skills in practice. This form of acquiring new knowledge in the exercise process is a very attractive diversion and bears the hallmarks of entertainment, which is a stepping stone from everyday life and is an important type of edutainment.

It is also worth mentioning that in the United States of America, there is a popular computer game called America's Army. It was created by the US Army for educational and promotional purposes for civilians in order to encourage them to join the army (America's Army). It shows in a subdued and methodical manner the specificity of service and field operations. In the form of this game, civilians learn the specificity of the army and the values in force here. In this way they gain valuable knowledge about the US Armed Forces. A few years ago, in Poland, Polish Defence Holding began work on a promotional video game, through which it would be possible to transform in a modern Polish soldier and play this role. It was supposed to be a kind of response to the game from the US Army, although here Polish vehicles and armaments would be depicted. Unfortunately, the idea has not been implemented, and nothing is being said about this project nor is anything known about it. In Poland, there is still no such game, or similar type of game for civilians and adepts to the army, which in a reliable and true way, without unnecessary aggression and brutality, distortions and exaggerations, would show the specifics of the army.

\section{Conclusions}

The planned priority of the transformation of the Polish Armed Forces in the Strategy for the Development of the National Security System of the Republic of Poland 2022 is to increase the level of their operational capabilities and to maintain the forces prepared to respond to current and new and unpredictable threats. At the same time, it is important to raise the level of military and general military training (Strategy for the development of the national security system of the Republic of Poland 2022). In addition, in the Defence Concept of the Republic of Poland, there is a record of analytical activity, which is to "rely on building an expert community in the Ministry of Defence, as well as integrating knowledge already existing in various institutions, public and non-public. Not only classic analytical techniques will be used, but also specialised IT tools or constantly developed war games and simulations" (The Defence Concept of the Republic of Poland, 2017).

With the development and progress of emerging new types of threats and newer forms of fighting, there is a growing need for more and more effective forms of education and improvement of military personnel. Forms of education that emotionally engage, activate to act and have elements of entertainment are therefore not perceived as aggravating. On the contrary, they are more interesting, as they cause a greater and faster absorption of information and 
knowledge. The abovementioned war games and simulations are an outstanding example of edutainment, which serves the multilateral education of the Polish Armed Forces for the needs of current and future threats.

\section{References}

1. America's Army, Available online: https://www.americasarmy.com/, 24.04.2018.

2. Gammadiscover, Available online: https://www.gammadiscover.pl/podstrony/edutainment/ eta ${ }_{2}$ 05.09. 2018.

3. Grydaktyka-opracowanie, Available online: http://bajkiozobotow.pl/wp-content/uploads/ 2016/11/grydaktyka-opracowanie.pdf, 05.09.2018.

4. https://www.documentingreality.com/forum/view.php?pg=ntfu, 24.04.2018.

5. Koncepcja Obronna Rzeczypospolitej Polskiej (2017).

6. Majewski, T. (2013). Rozwój zawodowy kadr dowódczych w Siłach Zbrojnych. Warsaw: Managerial Publishers PTM.

7. Moss, S. (2009). The entertainment industry: an introduction. Cambridge: Cambridge University Press.

8. PIT-RADWAR, Available online: www.pitradwar.com, 25.04.2018.

9. Polska Zbrojna, Available online: http://www.polska-zbrojna.pl/home/articleshow/ 5433?t=JCATS-preparations-of-for-mission, 23.04.2018.

10. Poniewozik, J., That's militainment! February 25, Available online: http://edition. cnn.com/ALLPOLITICS/time/2002/03/04/militainment.html, 23.04.2018.

11. Reinhardt, U. (2007). Edutainment: Bildung macht Spass. Hamburg: LIT Verlag.

12. Strategia rozwoju systemu bezpieczeństwa narodowego Rzeczypospolitej Polskiej 2022.

13. SuperData: Digital games and interactive media intelligence (n.d.). Available from: https://www.superdataresearch.com/market-data/market-brief-year-in-review/, 25.04.2018.

14. Szaban, J.M. (2011). Zarzadzanie zasobami ludzkimi $w$ biznesie $i w$ administracji publicznej. Warsaw: Difin.

15. Trends and Insights on Games and Interactive Media 2017 - Report (2017). Available online:http://progamedev.net/wp-content/uploads/2017/08/Games_and_Interactive_ Media_Report_2017_SuperData_Research.pdf, 25.04.2018.

16. Tummons, J., Ingleby, E. (2014). A-Z of lifelong learning. New York: Open University Press.

17. Wrzosek, M. (2018). Wojny Przyszłości; Doktryna, Technika, Operacje militarne. Warsaw: FRONDA Publisher. 